\title{
E-Demokrasi pada Perdebatan Publik di Twitter: Analisis Konten Polemik Pemecatan Pegawai Komisi Pemberantasan Korupsi (KPK)
}

\author{
Muhammad Iqbal Khatami ${ }^{1}$, Novi Kurnia ${ }^{2}$ \\ Magister Ilmu Komunikasi, Universitas Gadjah Mada \\ Email: muhammadiqbalkhatami@mail.ugm.ac.id
}

\begin{abstract}
Abstrak
Artikel ini memuat analisis konten e-demokrasi yang terbangun dalam media sosial Twitter. Peneliti melihat fenomena polemik publik dalam terhadap isu pemecatan Pegawai KPK RI yang tidak lulus Tes Wawasan Kebangsaan (TWK). Data diambil dari Twitter dengan total mencapai 7789 tweet dan komentar dikumpulkan dalam rentang tanggal 27 September hingga 2 Oktober 2021. Analisis data menggunakan Software Nvivo 12 Plus. Tweet diklasifikasikan ke dalam lima kategori yakni Logika dan Analisis, Menyebut Pemerintah, Informasi, Kekhawatiran dan Impresi. Tweet kemudian didistribusikan ke dalam sentimen positif, netral dan negatif untuk melihat peta perdebatan yang terjadi. Hasil penelitian menunjukkan perdebatan banyak terjadi dengan kategori Impresi yakni didominasi oleh perdebatan saling serang hingga labelling antar kelompok. Opinion leaders dalam perdebatan ini didominasi oleh akun influencer, media massa, dan aktivis anti korupsi.
\end{abstract}

Kata Kunci: KPK, Analisis konten, e-Demokrasi, Sentimen, Twitter

\begin{abstract}
This article contains an analysis of the e-democracy content that is built on Twitter social media. Researchers look at the phenomenon of public polemic on the issue of the dismissal of Indonesian KPK employees who do not pass the National Insight Test. Data is taken from Twitter with a total of 7789 tweets collected in the range from September 27 to October 2, 2021. Data analysis uses Nvivo 12 Plus Software. Tweets are classified into five categories namely Logic and Analytics, Mentions Government, Information, Concerns and Impressions. Tweets are then distributed into positive, neutral and negative sentiments to see a map of the public polemics. The results show that many debates occur in the Impression category, which is dominated by attack each other to labeling between groups. Opinion leaders in this polemics are dominated by influencer accounts, mass media, and anti-corruption activists.
\end{abstract}

Keywords: KPK, Content Analysis, e-Democracy, Sentiment, Twitter. 


\section{PENDAHULUAN}

Kehadiran media sosial mengubah cara penyebaran informasi menjadi semakin deras dan tak terbendung. Barber (2003) menyebutkan bahwa internet menjadi medium komunikasi alternatif yang demokratis sehingga memungkinkan masyarakat berkomunikasi dan bersuara tanpa adanya perantara. Batasan-batasan yang membentang semakin menipis dan menentang pola komunikasi hierarkis dalam sistem politik. Meskipun dalam praktiknya masih banyak tantangan seperti adanya represifitas yang terjadi dalam ruang-ruang digital, namun kehadiran internet dapat semakin memperkuat relasi antar masyarakat sipil dalam berpolitik dan berdemokrasi di dalam ruang publik. Dari fenomena ini, lahirlah kemudian istilah demokrasi digital (e-democracy) (Alwajih 2014).

Secara garis besar, yang membedakan konsep demokrasi secara umum dengan edemokrasi adalah adanya fasilitas teknologi yang dimanfaatkan sebagai medium dalam terjadinya proses demokrasi. Namun, E-demokrasi tidak dapat dilihat sebagai sistem tunggal yang berdiri sendiri, ia juga terikat dengan berbagai sistem di dalam pemerintahan sebuah negara dan beragam kultur di tengah masyarakat. E-demokrasi tidak sebatas mengintegrasikan media digital ke dalam sistem demokrasi guna memfasilitasi partisipasi masyarakat, karena media digital hanya sebatas medium dan bukan solusi sesungguhnya. Media elektronik dan digital tidak akan mempunyai makna sosial jika tidak diintegrasikan secara maksimal dengan sistem yang ada (Asenbaum 2018).

Demokratisasi di ruang siber mendorong segala jenis isu publik tidak lepas dari obrolan di ruang publik siber (Haezer 2018). Perdebatan terjadi lebih masif dan sulit terkontrol karena banyaknya akun yang bertebaran. Sebagai contoh perdebatan besar di ruang siber adalah ketika Pemilu Pemilihan Presiden (Pilpres) 2019 di mana masyarakat kita terpolarisasi antara "Cebong" dan "Kampret". Pendukung antar calon presiden pada saat itu saling serang dan hujat demi memenangkan opini publik di ruang siber (Hamid, Darwis, and Andriyani 2018). Tidak jarang, perdebatan yang berawal dari sosial media juga akan memengaruhi opini publik di dunia nyata.

Tak hanya terkait Pilpres 2019, perdebatan publik di media sosial juga terjadi untuk berbagai isu sosial politik lainnya. Dalam tulisan ini, peneliti akan melihat fenomena polemik publik dalam isu Pemecatan Pegawai Komisi Pemberantasan Korupsi (KPK) Republik Indonesia yang tak hanya mengundang banyak pro dan kontra di tengah masyarakat tapi juga menciptakan polarisasi. Isu Pemecatan Pegawai KPK merupakan isu bola salju yang berawal dari kebijakan pemerintah melakukan Revisi Undang-Undang KPK pada 2019 lalu. Tidak sedikit masyarakat yang memanfaatkan ruang siber sebagai ruang aktivisme digital dalam mengungkapkan ketidaksepakatan terhadap kebijakan yang dilahirkan tersebut. Sebaliknya, banyak warga yang pro terhadap kebijakan juga turut serta dalam perdebatan melalui ruang publik yang terbuka di media sosial.

Isu yang hangat pada tahun 2021 ini bermula dari pemecatan 58 orang pegawai KPK yang dipecat karena tidak lolos Tes Wawasan Kebangsaan (TWK). TWK tersebut digelar sebagai bentuk tindaklanjut dari peralihan status pegawai KPK menjadi Aparatur Sipil Negara (ASN). Dalam perbincangan di ruang siber, drama isu taliban dan HTI juga mewarnai pemecatan 58 pegawai KPK tersebut. Pemecatan 58 pegawai KPK menuai beragam kritikan dari banyak pihak. Pasalnya, ada narasi bahwa KPK terlihat sengaja ingin menendang keluar 
para pegawai yang terbukti berintegritas itu. Beragam ultimatum, protes, dan aktivisme lainnya dilakukan dalam ruang siber sebagai ruang publik baru. Muncul juga narasi pro yang mendukung pemecatan 58 pegawai KPK ini karena tidak lulus TWK dan dinilai memang tidak berkompeten.

Narasi pro dan kontra tersebut menunjukkan bahwa peran internet dan media sosial mendorong proses demokratisasi ruang publik dalam keterlibatan politik melalui jenis keterlibatan sipil tertentu, seperti melalui aktivisme berorientasi politik, di mana orang berpartisipasi dan berusaha saling memengaruhi dalam isu, masalah, sistem, dan struktur politik (Pontes, A., Hen and Griffiths 2018). Dalam proses demokrasi, konsep partisipasi publik dalam isu politik mengacu pada kegiatan yang mencakup tuntutan atau dukungan terhadap pemerintah (Bergström 2006). Partisipasi masyarakat dalam politik juga dapat dilihat sebagai hal di luar kegiatan yang ditujukan kepada pemerintah, karena sering kali melibatkan partisipasi aktor-aktor lain, termasuk partai politik, masyarakat, serta media.

Penelitian bertujuan mengetahui proses demokrasi yang terjadi di ruang publik digital dengan menggunakan metode content analysis terhadap teks terkait pemecatan 58 pegawai KPK yang muncul di salah satu media sosial yang paling banyak digunakan untuk ruang berpendapat yakni Twitter. Berdasarkan latar belakang yang peneliti uraikan di atas, penelitian mengenai demokrasi di media sosial penting dilakukan untuk melihat gambaran penerapan edemokrasi oleh masyarakat di ruang siber media sosial berdasarkan isu "Pemecatan Pegawai KPK yang tidak lolos TWK" beserta masalah-masalah yang terjadi seperti tindakan represifdan polemik perdebatan publik di dalamnya.

Menanggapi fenomena tersebut, peneliti merujuk Habermas (2008) yang menyatakan bahwa demokrasi digital hadir sebagai ruang adu gagasan warga yang berasosiasi secara bebas dalam masyarakat sipil. Habermas kemudian menambahkan bahwa demokrasi digital lebih banyak berfokus pada bagaimana wacana politik dimediasi. Sebab, internet muncul sebagai media komunikasi yang secara unik cocok untuk menyediakan beberapa arena untuk debat publik yang relatif spontan, fleksibel, dan, yang terpenting, diatur sendiri. Meskipun begitu, dalam praktiknya di Indonesia kadang kala wacana politik tidak termediasi dengan baik sebagaimana yang disampaikan oleh Habermas. Hal itu terjadi akibat banyaknya hambatan di ruang digital seperti munculnya hoaks, disinformasi, fenomena buzzer, dan lain sebagainya.

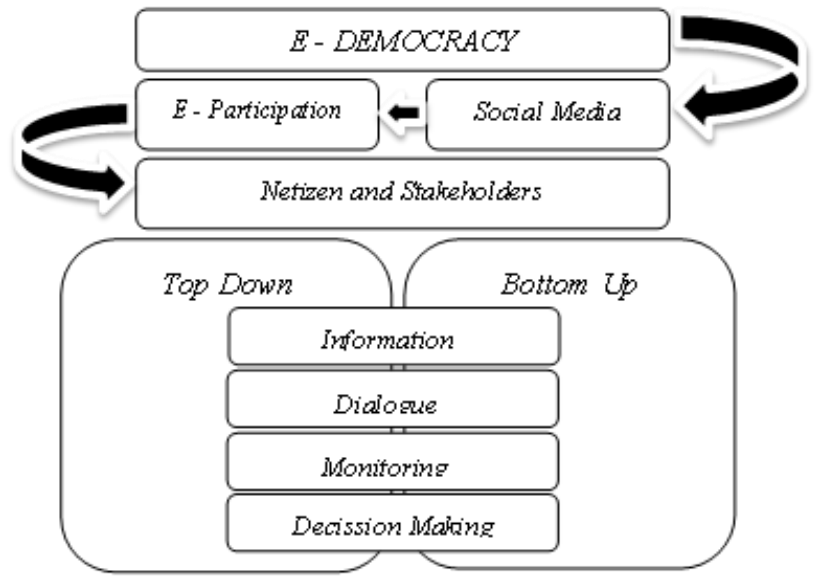

Gambar 1. Model E-Participation dalam E-Democracy di media sosial, diadopsi dari Kneuer (2016) 
Dalam penelitian ini, peneliti menggunakan konsep e-partisipation dalam praktik $e$ democracy dan menambahkan model di atas dengan merujuk pendapat Tsagarousianou (1999) yang menguraikan tiga aspek dari partisipasi politik; penyediaan informasi, musyawarah, dan partisipasi dalam pengambilan keputusan. Menurutnya, ketiga elemen ini menjadi sebuah struktur demokrasi yang juga berlangsung di dalam ruang siber dan difasilitasi oleh internet. Pertama, terkait dengan penyediaan informasi mengenai urusan publik dan kebijakan publik yang transparan dan aksesibel bagi publik maupun oleh pembuat kebijakan. Ini juga mengacu pada tindakan mencari, mengumpulkan, berbagi, dan menghasilkan informasi politik hingga menjadi diskursus di tengah masyarakat.

Kedua, berkaitan dengan hadirnya dialog dalam ruang publik antara publik, pemerintah, dan pihak lain. Dialog dan perdebatan akan mempengaruhi partisipasi politik dalam cara masyarakat menyampaikan pendapat, tuntutan, debat, negosiasi, dan lain sebagainya terhadap isu tertentu. Terakhir, terkait dengan pengambilan keputusan sebagai salah satu unsur partisipasi politik yang dapat diwujudkan dalam tindakan kolektif dalam pengambilan kebijakan. Mauliansyah (2016) menyebut tindakan kolektif dapat dilihat dalam dua dimensi, yaitu partisipasi yang terlembaga dan terwakili, dan partisipasi yang mandiri. Dimensi kedua paling potensial dalam aksi kolektif, karena model interaksi yang ditawarkan internet memudahkan publik dalam menginisiasi partisipasi mandiri dan otonom.

Referensi lain terkait analisis sentimen dijelaskan oleh Fathan Hidayatullah and Sn (2014) sebagai studi berbasis komputasi mengenai emosi, pendapat, sikap, penilaian, padangan dari kumpulan teks yang berfokus untuk mengekstraksi, mengidentifikasi atau mendapatkan karakteristik sentimen dalam sebuah unit teks menggunakan metode NLP (Natural Language Processing), statistik atau mesin pembelajaran. Analisis Sentimen adalah proses klasifikasi dokumen teks ke dalam beberapa klasifikasi seperti sentimen positif, netral dan negatif (Kurnia, N. \& Savirani 2021)

\section{METODOLOGI PENELITIAN}

Jenis penelitian ini menggunakan pendekatan penelitian kualitatif yang didefinisikan oleh Auerbach \& Silverstein (dalam Sugiyono 2011) sebagai pendalaman suatu makna melalui analisis dan penafsiran. Penelitian kualitatif dilakukan dengan membandingkan dan memberikan informasi yang kredibel yang dapat diperoleh (Moleong 2012).

Metode penelitian menggunakan analisis isi (content analysis) yang berisi pembahasan mendalam terkait isi suatu informasi tertulis atau tercetak dalam media yang dapat digunakan dalam penelitian kualitatif (Franzosi 2008). Data kemudian diolah dengan proses analisa Big Data guna merangkum percakapan yang menggambarkan partisipasi masyarakat di media sosial Twitter, dalam hal ini yaitu terkait polemik publik pada isu pemecatan pegawai KPK tidak lulus TWK. Dalam memproses Big Data yang merangkum polemik publik melalui konten yang dipublikasikan di Twitter, analisis sentimen dapat digunakan sebagai pendekatan untuk melihat perdebatan yang terbangun dan memetakan data yang ada (Nomleni, Hariadi, and Purnama 2014). Selanjutnya data diproses menggunakan Software Nvivo 12 Plus dengan sumber sekunder yang diambil dari capture percakapan di sosial media Twitter yang relevan terkait isu 'Pemecatan Pegawai KPK RI yang tidak lolos Tes Wawasan Kebangsaan'. Adapun word query (kata pencarian) yang digunakan adalah; "TWK KPK”. 
Capture Tweet dilakukan dalam rentang waktu selama 7 hari yakni dari 27 September hingga 2 Oktober 2021. Rentang waktu ini diambil sehubungan dengan momentum surat pemecatan yang dikeluarkan di 30 September 2021 (CNN Indonesia 2021). Berdasarkan hasil capture, ada sebanyak 7789 komentar yang berasal dari beragam sumber tweet. Pemerosesan data tweet didasarkan pada kategorisasi polemik publik yang telah peneliti susun. Kategorisasi polemik publik dapat dilihat berdasarkan tabel berikut:

Tabel 1. Kategorisasi Polemik Publik

\begin{tabular}{|c|c|c|}
\hline No. & Kategori & Definisi \\
\hline 1. & Logika dan Analisis & $\begin{array}{l}\text { Komentar yang merujuk pada pendapat para ahli, } \\
\text { hasil penelitian, sumber ilmiah lainnya. Komentar } \\
\text { yang mencoba menganalisis dan beropini tentang } \\
\text { pemecatan pegawai KPK RI tidak lulus Tes } \\
\text { Wawasan Kebangsaan }\end{array}$ \\
\hline 2. & Menyebut Pemerintah & $\begin{array}{l}\text { Komentar yang mengaitkan pemecatan pegawai } \\
\text { KPK terhadap Pemerintah }\end{array}$ \\
\hline 3. & Informasi & $\begin{array}{l}\text { Komentar yang berisi informasi terkait } \\
\text { pemecatan pegawai KPK RI dalam bentuk artikel } \\
\text { berita }\end{array}$ \\
\hline 4. & Kekhawatiran & $\begin{array}{l}\text { Komentar yang mengungkapkan kekhawatiran } \\
\text { terhadap peristiwa pemecatan pegawai KPK RI } \\
\text { yang tidak lulus Tes Wawasan Kebangsaan }\end{array}$ \\
\hline 5. & Impresi & $\begin{array}{l}\text { Komentar yang tidak termasuk empat indikator di } \\
\text { atas seperti sarkasme, sindiran, optimisme, } \\
\text { humor, dan lain sebagainya }\end{array}$ \\
\hline
\end{tabular}

Sumber: Diadaptasi dari Yamada (2020)

Penggolongan sentimen publik didasarkan pada pengkategorisasian dari tabel di atas. Sentimen publik digolongkan ke dalam sentimen positif, negatif, dan netral (Shull, Jiang, S., Zhu, and Zhu 2019). Pesan yang mendukung pemecatan pegawai KPK RI diidentifikasi sebagai sentimen positif, dan pesan yang menolak dan mengkritisi pemecatan pegawai KPK RI diidentifikasi sebagai sentimen negatif. Kategori "netral" termasuk cerita dengan nada netral atau campuran.

Dalam memulai content analysis, peneliti menggunakan model sentimen yang terdiri dari lima fase yakni fase pengumpulan data, fase penyimpanan data, fase preprocessing data, fase klasifikasi, dan fase presentasi data, diadopsi dari (Ragini, Anand, and Bhaskar 2017). Usulan model digambarkan pada Gambar 2 berikut: 


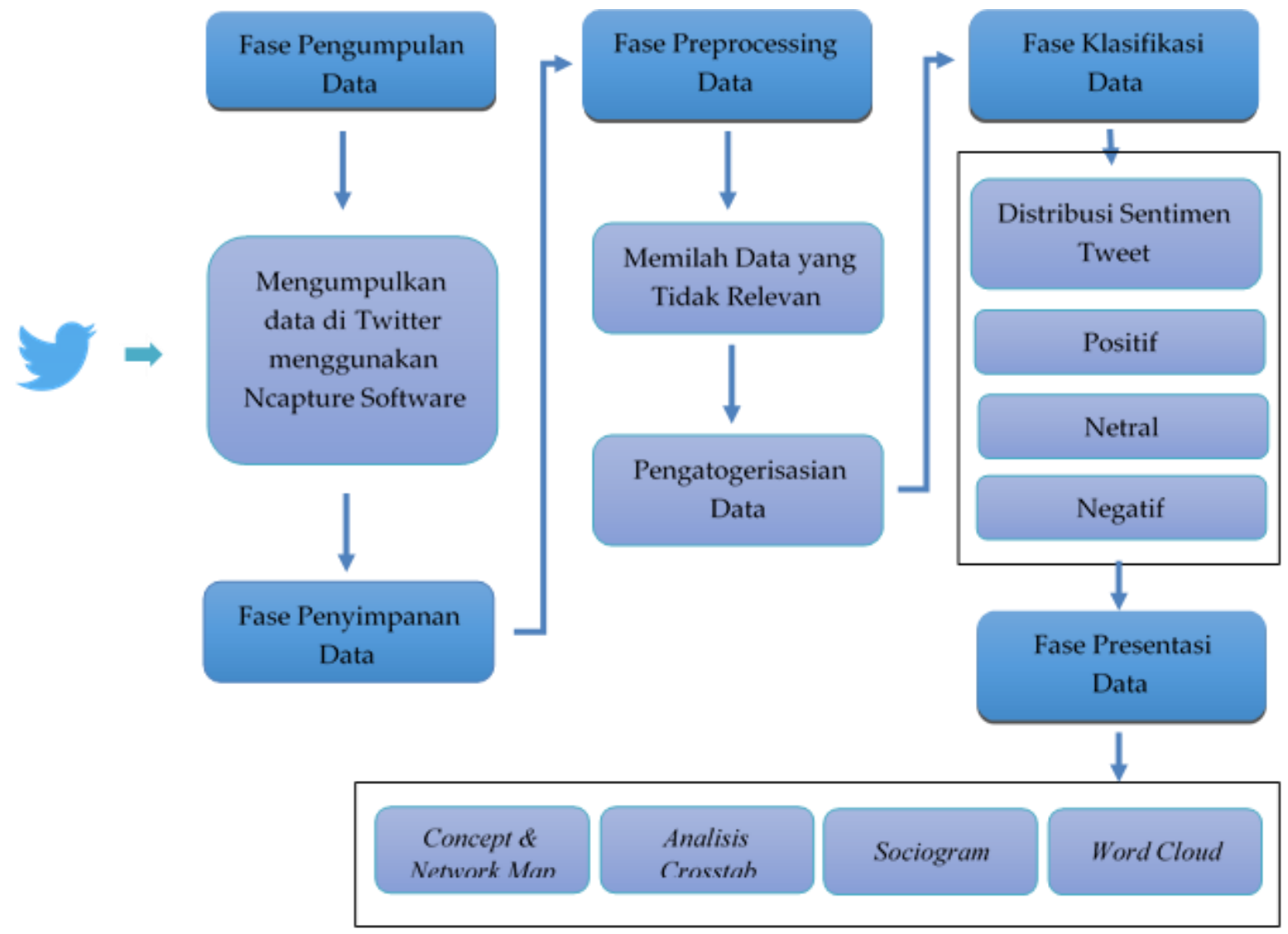

Gambar 2. Model kategorisasi dan klasifikasi data, diadopsi dari Ragini et al. (2017)

Berdasarkan model di atas, setelah data yang dikumpulkan peneliti kemudian melakukan preprocessing data untuk memilih data yang relevan. Sebagai contoh banyak tweet yang tidak menjurus kepembahasan sesuai word query "TWK KPK", namun beberapa menggunakan word query tersebut untuk membagikan konten lain seperti konten promosi, dengan tujuan agar kontennya ikut trending dengan kata kunci tersebut. Setelah itu, peneliti melakukan klasifikasi data berdasarkan distribusi sentimen yaitu positif, netral dan negatif.

Tahapan selanjutnya, peneliti melakukan presentasi data dengan Nvivo 12 plus untuk mempresentasikan data adalah analisis crosstab, analisis word cloud, dan discource network analysis. Analisis crosstab digunakan untuk membuat tabel kontingensi dari distribusi frekuensi variabel multivarian (Joosten et al. 2012). Sedangkan analisis penelitian teks yang menggunakan word cloud adalah untuk mencari makna, kata-kata, dan konteks yang berkaitan. Penggunaan discourse network analysis untuk melihat peta obrolan di Twitter terkait isu yang diangkat. Tujuan dari digunakannya fitur-fitur tersebut adalah untuk mempermudah memetakan distribusi sentimen dari data yang diolah.

\section{HASIL DAN PEMBAHASAN}

Dalam hal demokratisasi, Gramsci, Antonio, dan Quintin Hoare (1971) meletakkan ide dasar mengenai bagaimana terbentuknya ruang publik yang bebas akan tetapi tetap memiliki komitmen dalam sosial politik untuk dapat saling mengisi dengan tujuan kemajuan dan keadilan bagi masyarakat, serta menciptakan masyarakat yang adaptif dengan sifat terbuka 
dalam menghadapi dinamika perubahan. Kondisi proses demokrasi yang menggembirakan adalah adanya kehadiran sosial media sebagai medium baru demokratisasi secara digital. Peran aktif politik masyarakat dalam kegiatan politik menjadi dipermudah, terutama dalam hal pengawalan kebijakan. Kehadiran sosial media menjadi ruang baru bagi masyarakat untuk mengekspresikan diri, menggali informasi, hingga memobilisasi massa.

Distribusi jumlah tweet yang membincangkan terkait isu pemecatan pegawai KPK yang tidak lulus TWK dapat dilihat dalam gambar 3. Pada gambar 3, terlihat bahwa distribusi tertinggi ada pada tanggal 1 Oktober 2021 sebanyak 2976 tweet, terbanyak kedua ada pada tanggal 30 September 2021 sebanyak 2327 tweet, dan distribusi terendah ada pada 5 Oktober 2021 sebanyak 72 tweet.

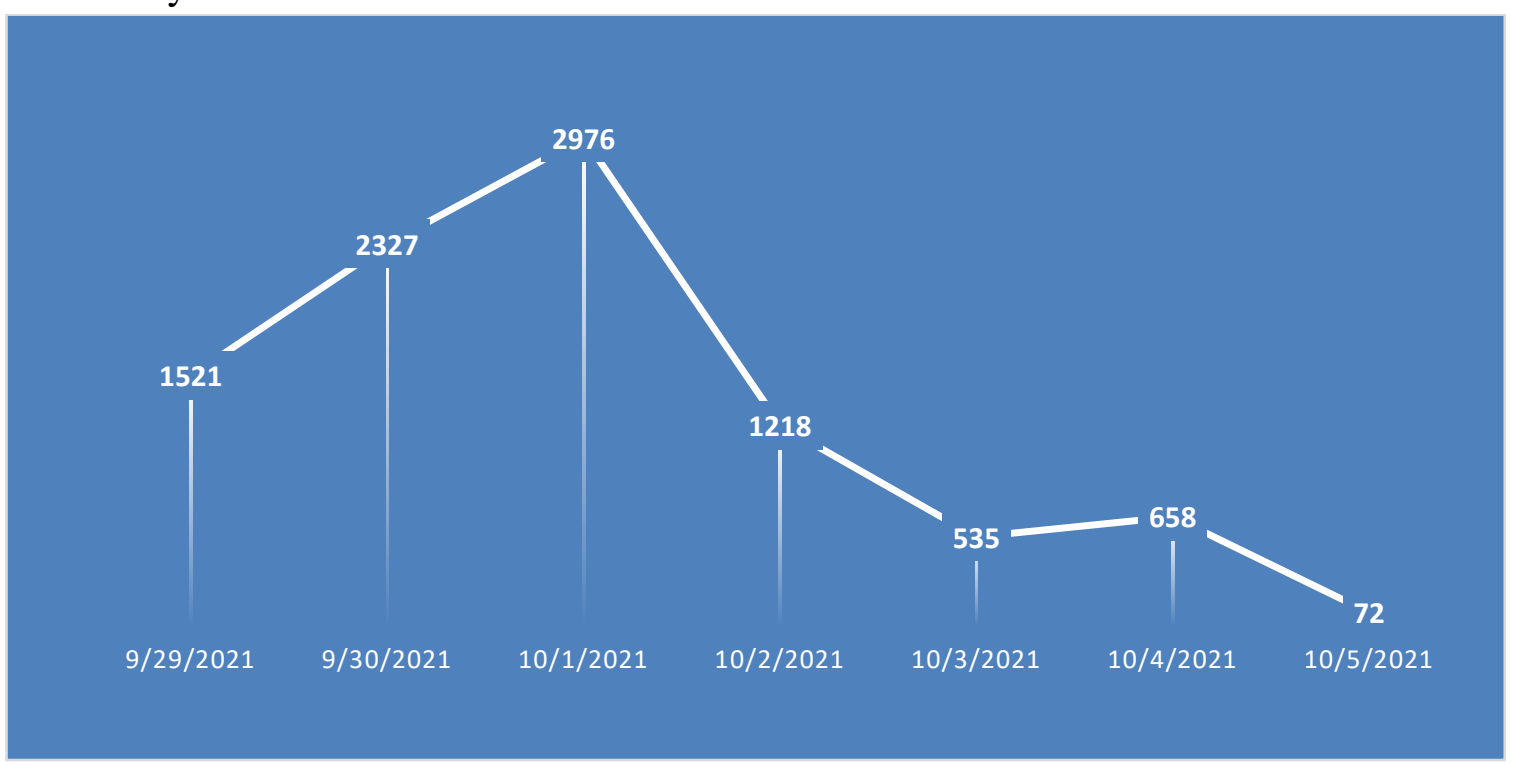

Gambar 3. Distribusi tweet "TWK KPK”, data olahan peneliti, 2021.

Dalam gambar 3 terlihat bahwa polemik publik terkait dengan isu pemecatan 58 pegawai KPK RI akibat tidak lulus Tes Wawasan Kebangsaan (TWK) sangat tinggi. Dalam 7 hari, ada 7789 tweet dan komentar yang isinya menyinggung kata kunci "twk kpk". Distribusi tweet tertinggi ada pada tanggal 1 Oktober 2021 sebanyak 2976 tweet dan 30 September 2021 sebanyak 2327 tweet. Tanggal 30 September 2021 merupakan momentum pemberhentian secara resmi 58 pegawai KPK yang tidak lulus TWK. Sehingga, tidak heran jika di tanggal 30 September 2021 hingga 1 Oktober 2021 intensitas tweet terkait isu pemecatan pegawai KPK yang tidak lulus TWK ini memuncak.

Polemik publik atas isu pemecatan pegawai KPK RI yang tidak lolos TWK dapat dikategorisasikan berdasarkan gambar 4. 


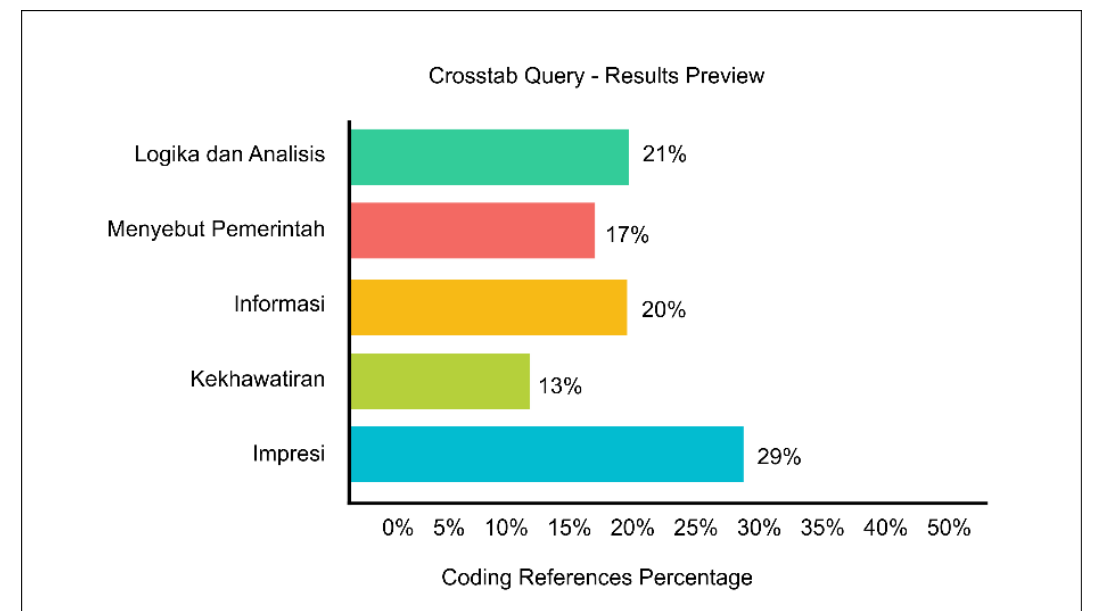

Gambar 4. Persentase kategorisasi polemik publik, data olahan peneliti, 2021.

Peneliti mengklasifikasikan pesan ke dalam beberapa kategori. Kategori dengan persentase tertinggi adalah tweet dengan kategori "Impresi" sebanyak 29\%, tweet tersebut bernada seperti kritik, sarkasme, sindiran, optimisme, humor, dan lain sebagainya yang tidak termasuk ke dalam empat kategori lain yang telah diuraikan pada Tabel 1.

Kategori terbanyak kedua ada pada "Logika dan Analisis" yakni sebanyak $21 \%$. Kategori ini banyak diisi oleh para pengamat politik, aktivis, politisi dan pejabat pemerintahan. Sedangkan terbanyak ketiga adalah "Informasi" sebanyak 20\%. Kategori informasi banyak diisi oleh tweet pemberitaan akun-akun media massa. Sebab, sebagian besar aktor yang memberikan analisis dan logika terhadap isu ini banyak diberitakan melalui media massa. Dalam demokratisasi, media massa memiliki peranan penting sebagai penyedia informasi dan media monitoring yang dapat mempermudah partisipasi digital masyarakat dalam mengawal sebuah isu atau kebijakan (Kneuer 2016).

Kategori terbanyak ke empat adalah "Menyebut Pemerintah" sebanyak 17\%. Dalam temuan data peneliti, banyak warganet yang mengaitkan masalah ini dengan pemerintahan baik eksekutif dan legislatif. Presiden Joko Widodo banyak disebut dalam perdebatan ini karena dianggap bertanggungjawab dalam masalah pemecatan pegawai KPK RI yang tidak lulus TWK. Namun, sebagian pihak yang menyebut Jokowi juga membangun narasi bahwa memang seyogyanya Jokowi tidak terlibat dalam urusan ini untuk menjaga independensi KPK. Penyebutan pemerintah dalam polemik publik di isu ini menunjukkan bahwa warganet berusaha membangun dialog melalui ruang digital yang juga merupakan konsep $e$ partisipation yang dicetuskan oleh Kneuer. Komunikasi yang terarah antara pemerintah dan masyarakat menjadi praktik pragmatis dan kewajiban moral yang berangkat dari prinsip demokrasi (Kent 2013). Teori demokrasi menonjolkan urgensi pemerintah untuk bisa berkomunikasi secara terbuka, interaktif, dan partisipatif.

Selain itu, kategori "Kekhawatiran" merupakan kategori paling rendah yakni $11 \%$. Kategori Kekhawatiran diisi oleh tweet dengan nada mengkhawatirkan suatu keadaan yang akan datang. Pihak pro mengkhawatirkan jika pegawai yang tidak lulus TWK tidak dipecat maka akan terjadi masalah. Sedang pihak kontra dominan mengkhawatirkan adanya pelemahan dalam tubuh KPK. 
Dalam melihat polemik yang terjadi, peneliti memilah berdasarkan sentimen. Pada Gambar 5 menujukkan distribusi sentimen publik yang direpresentasikan dalam tweet yang ter-capture. Sentimen positif merupakan tweet yang mendukung pemecatan pegawai KPK RI yang tidak lolos TWK, dan sentimen negatif adalah yang menolak, menentang dan mengkritisi pemecatan tersebut.

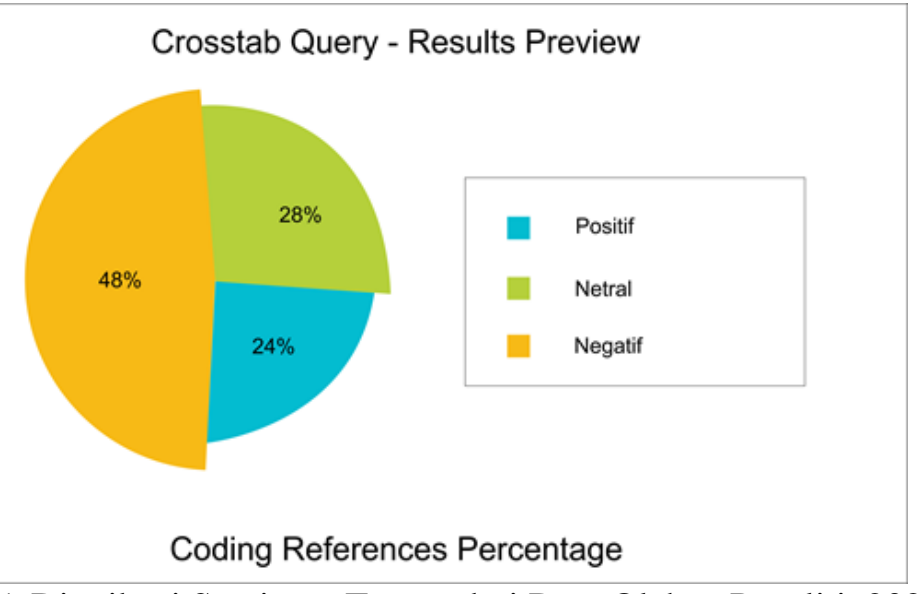

Gambar 5. Distribusi Sentimen Tweet, dari Data Olahan Peneliti, 2021.

Tweet bernada sentimen negatif sebanyak $48 \%$, yang artinya mayoritas warganet yang terlibat dalam polemik ini menentang, mengkritisi dan menolak terkait pemecatan yang dilakukan terhadap 58 pegawai KPK akibat tidak lulus TWK. Sementara itu, tweet dengan sentimen positif atau diartikan mendukung KPK melakukan pemecatan ini ada sebanyak $24 \%$. Sedangkan tweet dengan sentimen netral ada sebanyak 28\%. Di sini terlihat bahwa sentimen positif menempati urutan paling rendah dibandingkan sentimen netral dan sentimen negatif.

KPK mulai ramai dikritisi oleh publik sejak adanya revisi Undang-undang KPK pada 2019 lalu. Sehingga, isu pemecatan ini menjadi titik bara kekecewaan publik yang menganggap KPK semakin dilemahkan (Isnadi, 2021). Penggunaan analisis sentimen untuk melihat keberpihakan seseorang dari konten yang ia publikasikan sejalan dengan penelitian yang pernah dilakukan oleh Rozi \& Dahlan (2012) yang menyebut bahwa analisis sentimen dapat dilakukan untuk menilai opini dan melihat kecenderungan sebuah opini terhadap suatu topik dan isu baik negatif maupun positif.

Pada gambar 6, peneliti mengambil satu tweet yang memiliki impresi tertinggi dari masing-masing sentimen positif, netral dan negatif sebagai representasi untuk menjadi gambaran bagaimana tiap sentimen dinarasikan dalam konten. Pada sentimen positif, peneliti mengambil tweet yang ditulis oleh @GreatOfKratos yang isi tweet-nya bernada positif denga mengaitkan pemecatan tersebut dengan menyebutkan ada kegiatan melenceng yang dilakukan oleh pegawai KPK. Pada sentimen netral, peneliti mengutip tweet dari @ detikcom yang memberitakan terkait pemecatan secara resmi oleh KPK. Sedangkan pada tweet negatif peneliti mengutip tweet oleh @febridiansyah yang menyampaikan dukacitanya terhadap pemecatan pegawai KPK tersebut. 


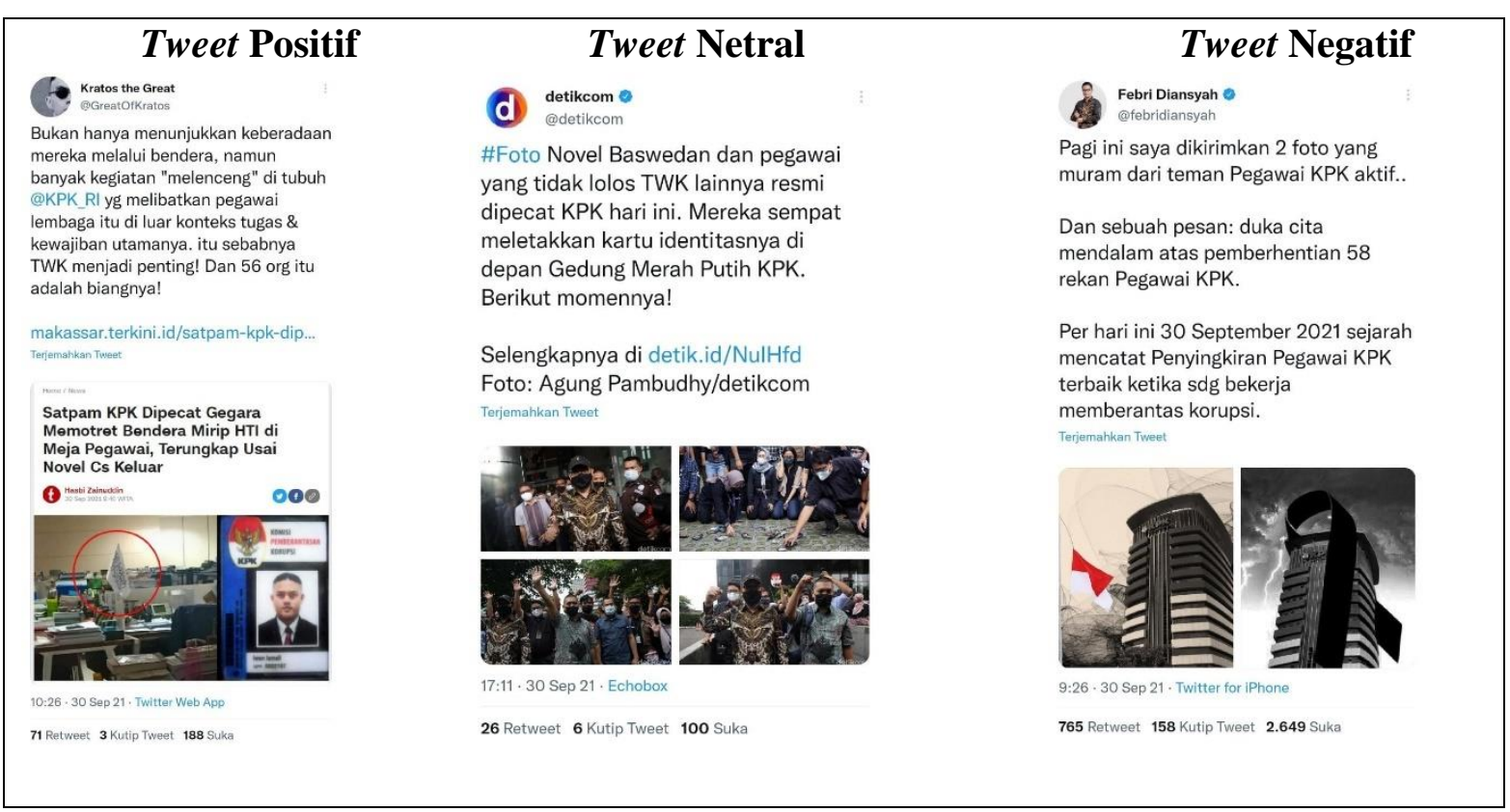

Gambar 6. Representasi tweet di tiap Sentimen, dari data olahan peneliti, 2021.

Gambar 7 menunjukkan persentase kategori dalam sentimen positif. Pada sentimen positif, kategori tertinggi adalah "Impresi" sebanyak 53\%. Dalam polemik ini, tweet Impresi banyak berisi hujatan dan perdebatan hingga saling sindir dan labelling antar warganet. Pihak dengan posisi mendukung KPK di bawah kepemimpinan Firli Bahuri menganggap bahwa pemecatan 58 orang tersebut adalah langkah tepat dengan beragam isu yang dimunculkan seperti isu 58 orang tersebut terindikasi taliban, khilafah hingga dianggap memang tidak layak di KPK. Sedangkan kategori lainnya secara berurutan diisi oleh "Logika dan Analisis" sebanyak 28\%, kategori "Menyebut Pemerintah" sebanyak 11\%, dan kategori "Informasi" serta "Kekhawatiran" sebanyak masing-masing $4 \%$.

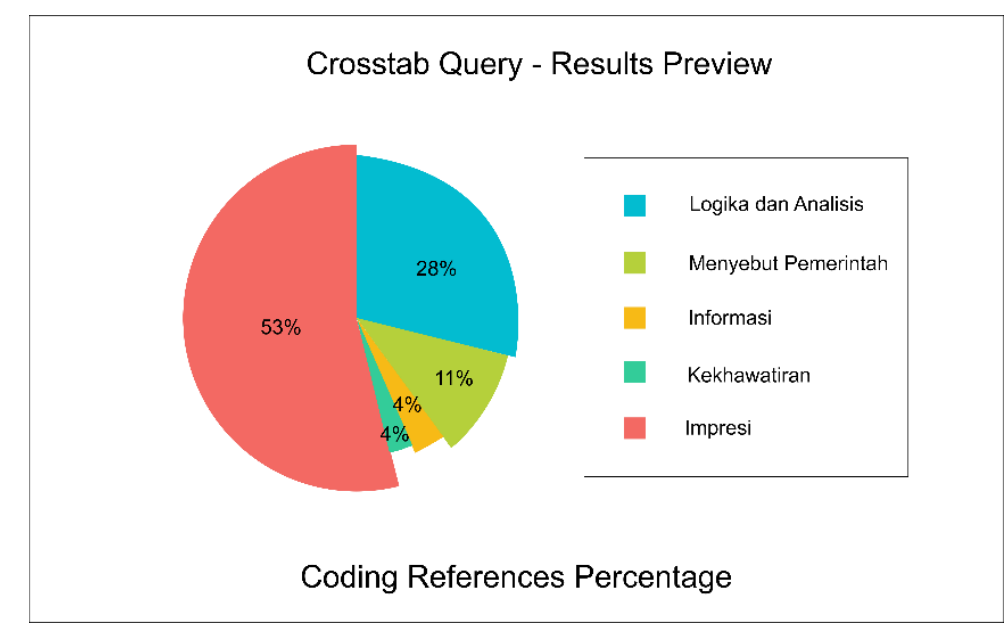

Gambar 7. Persentase kategori dalam Sentimen Positif, data olahan peneliti, 2021 
Gambar 8 menunjukkan persentase pada sentimen netral. Tweet yang banyak didistribusikan pada sentimen netral ada pada kategori "Informasi" sebanyak 56\%. Sebagaimana pada Gambar 6, tweet kategori Informasi banyak diisi oleh tweet pemberitaan oleh media massa. Sedangkan kategori-kategori lain secara berurutan diisi oleh kategori "Menyebut Pemerintah" sebanyak 20\%, kategori "Impresi" sebanyak 14\%, kategori "Logika dan Analisis" sebanyak 7\%, dan kategori "Kekhawatiran" sebanyak 3\%.

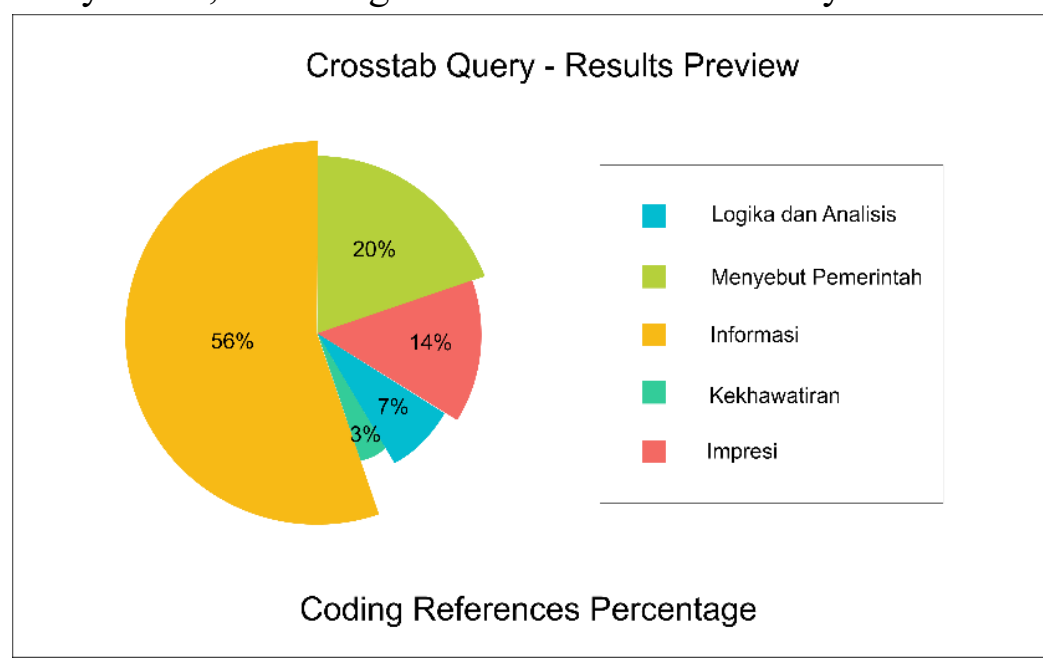

Gambar 8. Persentase kategori dalam Sentimen Netral, data olahan peneliti, 2021

Gambar 9 menunjukkan persentasi kategori pada distribusi sentimen negatif. Kategori dengan persentase tertinggi ada pada kategori "Impresi" sebanyak 27\%. Sama seperti di sentimen positif, isi tweet banyak diisi saling sindir oleh warganet yang menentang pemecatan pegawai KPK tersebut. Kategori terbanyak kedua diisi oleh "Logika dan Analisis" sebanyak $25 \%$. Kategori ini banyak diisi oleh tweet yang berisi analisis dan pandangan logis terkait dengan permasalahan pemecatan pegawai KPK yang tidak lulus TWK tersebut. Sedangkan kategori lain diisi oleh "Menyebut Pemerintah" sebanyak 21\%, "Informasi" sebanyak 14\%, dan "Kekhawatiran" sebanyak 11\%.

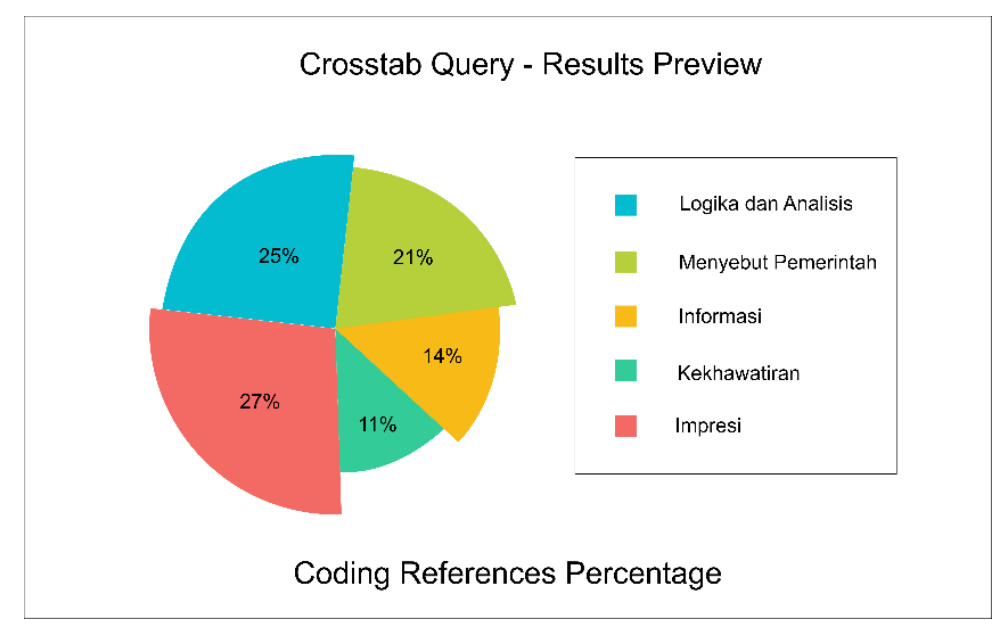

Gambar 9. Persentase kategori dalam Sentimen Negatif, data olahan peneliti, 2021. 
Impresi menjadi terbanyak dalam dua sentimen yakni sentimen positif dan negatif. Hal tersebut menunjukkan bahwa terjadi perdebatan yang menjurus ke saling serang antara kubu pro dan kontra terhadap isu ini. Sementara sentimen netral didominasi oleh kategori Informasi, sebab sentimen netral banyak diisi oleh pemberitaan media massa yang mana memang berdiri di sisi tengah dalam memberitakan sebuah isu. Media massa memiliki peranan penting dalam demokratisasi di ruang siber. Media massa harus tetap hadir secara proporsional dalam menyiarkan berita dan sadar akan peran dan fungsinya sebagai penyedia informasi, edukasi, kontrol sosial, dan perekat sosial duna mendorong budaya demokrasi yang berkualitas (Poentarie 2015).

Peneliti kemudian memproses data Word Cloud untuk menunjukkan kata yang paling banyak muncul dalam perbincangan. Data Word Cloud diproses dari kumpulan tweet di tiap sentimen yaitu positif, netral dan negatif. Word Cloud dibagi persentimen agar mempermudah melihat isu dan kata-kata apa yang paling banyak disebut dalam setiap sentimen.

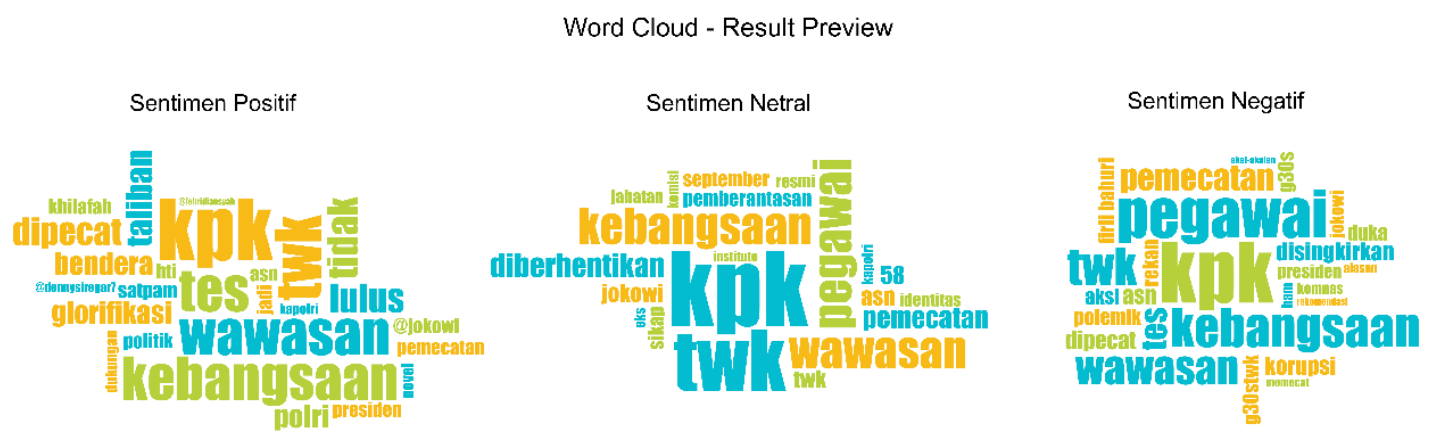

Gambar 10. Wordcloud Sentimen Positif, Netral dan Negatif, data olahan peneliti, 2021.

Berdasarkan hasil Word Cloud dalam setiap sentimen, kata yang paling banyak muncul dalam setiap sentimen cenderung sama yakni "kpk", "wawasan", "kebangsaan", dan "twk". Kata-kata tersebut lumrah banyak disebut sebab merupakan kata kunci dari isu yang dibahas. Dalam hal ini peneliti mencoba melihat kata-kata yang berbeda dalam tiap sentimen.

Dalam distribusi sentimen positif, muncul kata "glorifikasi". Kata ini banyak disebut dengan narasi bahwa 58 orang yang dipecat dari KPK akibat tidak lulus TWK terlalu diglorifikasi dan dielu-elukan. Ada juga kata "satpam", "hti”, dan "bendera" yang muncul berkaitan dengan adanya narasi yang menyebut adanya satpam yang dipecat akibat menemukan bendera "HTI" di meja salah satu pegawai yang dipecat. Narasi ini pertama kali di-tweet oleh akun @dennysiregar7 dengan isi:

"Iwan Ismail satpam lama @ KPK_RI dipecat Novel Baswedan, karena memotret meja kerja yang ada bendera HTI. Novel Baswedan dipecat @ kpk karena tdklolos TWK. Orang bilang hidup itu tidak adil. Tapi ada saat keadilan itu datang dalam bentuk pembalasan yg lebih menyakitkan.." (Di-Tweet oleh @ dennysiregar7 pada 1 Oktober 2021)

Dalam distribusi sentimen netral, kata-kata yang banyak muncul cenderung kata-kata normatif pemberitaan yang tidak jauh dari kata kunci utama isu ini, seperti "kpk", "twk", 
“pegawai”, “diberhentikan”, “wawasan”, dan “kebangsaan”. Kata-kata ini banyak digunakan oleh media massa yang juga meng-tweet pemberitaannya di Twitter.

Sedangkan dalam distribusi sentimen negatif, muncul kata hashtag \#g30stwk. Hashtag ini digunakan oleh pihak yang kontra terhadap pemecatan. G30STWK merupakan plesetan dari G30SPKI. Di mana banyak warganet yang juga mengaitkan isu pemecatan yang terjadi di tanggal 30 September 2021 dengan peristiwa pemberontakan Partai Komunis Indonesia (PKI) yang diperingati setiap tanggal 30 september. Narasi ini berawal dari statemen dari Giri Suprapdiono yang merupakan salah satu pegawai KPK yang dipecat. Terlihat dari tweet akun @ kumparan berikut:

"Direktur Sosialisasi dan Kampanye Antikorupsi nonaktif KPK Giri Suprapdiono mengistilahkan, pemberhentian pegawai KPK itu sebagai G30S/TWK karena bertepatan dengan peristiwa G30S/PKI \#JernihkanHarapan \#G30STWK”. (Di-

Tweet oleh @ kumparan pada 30 September 2021)

Berdasarkan contoh-contoh tweet dari distribusi sentimen positif dan negatif, kita bisa melihat bahwa perdebatan memang banyak didominasi oleh Impresi, dengan cara saling memberi label antar pihak. Seperti pihak pro pemecatan yang memberi label "Taliban" dan "HTI". Juga pihak kontra yang memberi label "PKI". Dalam analisis Word Cloud, peneliti menemukan perbedaan penggunaan kata kerja pasif yang bermakna sama di tiap sentimen yaitu, pada sentimen positif kata kerja yang banyak digunakan adalah "dipecat", kemudian pada sentimen netral banyak menggunakan kata "diberhentikan", dan pada sentimen negatif banyak menggunakan kata "disingkirkan".

Kata kerja pecat cenderung bermakna kegiatan memberhentikan seorang pekerja oleh pimpinan karena melakukan kesalahan, tidak becus, dan lain-lain. Penggunaan kata ini sejalan dengan narasi pada sentimen positif yang setuju terhadap pemecatan pegawai KPK tidak lulus TWK. Pada sentimen netral banyak menggunakan kata diberhentikan. Kata diberhentikan berkonotasi netral dan dalam konteks ini banyak digunakan oleh media. Hal ini berkaitan juga dengan kode etik jurnalistik yang melarang media massa menggunakan bahasa atau bersikap tendensius dan berpihak. Sedangkan pada sentimen negatif, kata kerja yang banyak digunakan adalah disingkirkan. Disingkirkan memiliki makna yang menggambarkan adanya pemberhentian secara sengaja untuk menghilangkan orang-orang terkait dari lembaga tersebut. Perbedaan penggunaan kata kerja ini menggambarkan bahwa penggunaan kata dapat menjadi representasi dari bagaimana keberpihakan seseorang dalam membangun narasi perdebatan.

Perdebatan publik dan aktivisme digital juga seringkali memanfaatkan fitur hashtag untuk memudahkan pengelompokkan atau keberpihakan. Sebuah gerakan juga bisa terkenal karena hashtag. Pada Gambar 11 menggambarkan hashtag yang paling sering digunakan oleh warganet dalam polemik isu pemecatan pegawai KPK RI tidak lulus Tes Wawasan Kebangsaan. 


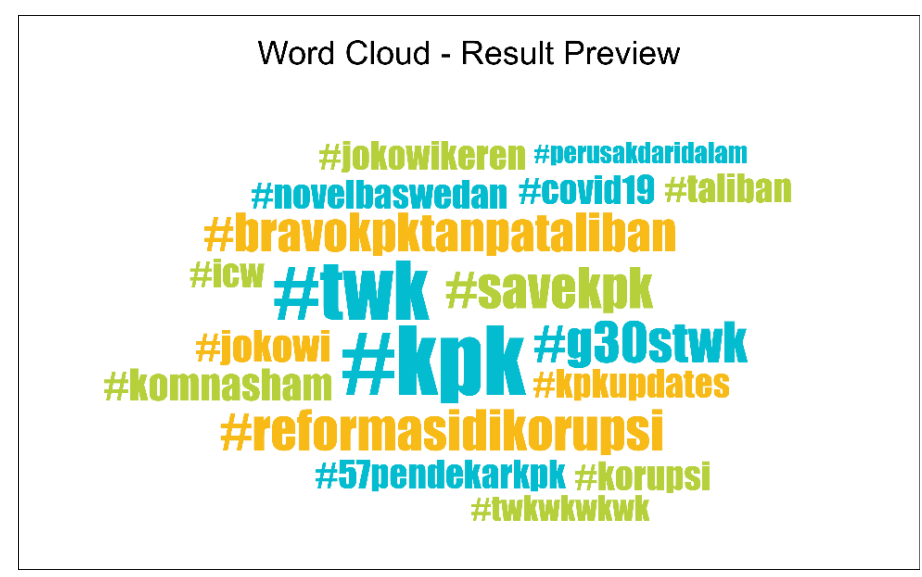

Gambar 11. World Cloud Hashtag terbanyak digunakan

Dalam data Wordcloud Hashtag, hashtag yang digunakan oleh kelompok pro beberapa diantaranya adalah \#bravokpktanpataliban. Sedangkan kelompok kontra menggunakan hashtag diantaranya \#reformasidikorupsi, \#g30stwk, \#twkwkwkwk, hingga \#perusakdaridalam. Penggunaan hashtag selain menunjukkan standpoint dari warganet, juga menjadi sarana decission making warganet dalam berpihak yaitu berusaha membangun narasi untuk memengaruhi orang-orang agar ikut berpihak.

Peneliti berusaha melihat akun-akun dominan dalam memantik polemik terkait isu ini. Pada Gambar 12 menunjukkan 10 akun Twitter yang paling banyak menyinggung soal isu pemecatan pegawai KPK RI yang tidak lulus Tes Wawasan Kebangsaan.

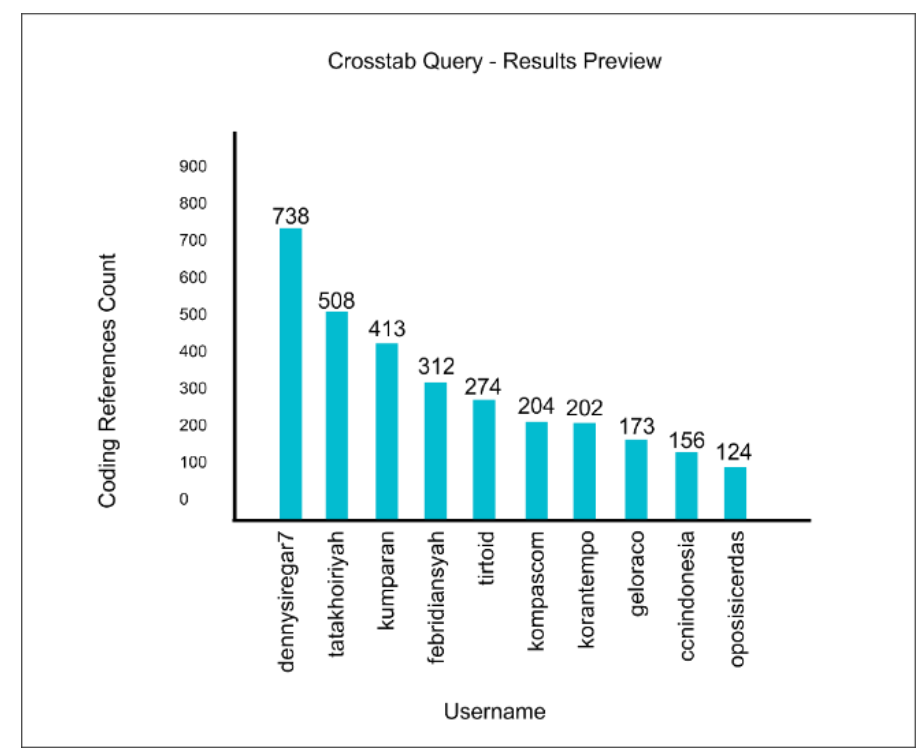

Gambar 12. Akun Twitter dengan References terbanyak, olahan peneliti, 2021.

Dari hasil data 10 akun dengan references terbanyak yang diperoleh, media massa mendominasi di antaranya ada @kumparan, @tirtoid, @korantempo, @kompascom, @geloraco, dan @cnnindonesia. Ada juga akun @dennysiregar7 yang cukup banyak memantik perdebatan publik seperti tweet-nya yang terkait dengan pemecatan satpam yang melihat bendera "HTI” di meja salah satu pegawai KPK. Pengaruh akun @dennysiregar7 yang 
cukup kuat juga tidak terlepas dari jumlah followers Twitternya yang saat ini mencapai 1,1 juta. Ada juga akun @oposisicerdas dengan followers 111 ribu dan rutin mengomentari isuisu terkini, salah satunya adalah ketika polemik isu KPK ini.

Akun Twitter yang memiliki jumlah pengikut yang banyak seperti akun @ dennysiregar7 dan @oposisicerdas, juga dikenal dengan beberapa istilah sebagai seorang buzzer atau influencer atau selebtwit. Di dalam ranah komunikasi, konsep ini hampir sama dengan apa yang disebut dengan 'opinion leaders' atau pemuka opini (Hananto 2014).

Akun@tatakhoriyah dan@febridiansyah juga menjadi akun dengan references terbanyak dalam isu ini. @ tatakhoiriyah merupakan akun dari Tata Khoiriyah yang merupakan salah satu pegawai KPK yang dipecat. Sedangkan @febridiansyah merupakan akun dari Febri Diansyah yang merupakan mantan juru bicara KPK yang saat ini aktif sebagai aktivis anti korupsi di Indonesian Corruption Watch (ICW). Febri Diansyah memang kerapkali bersuara menentang pemecatan pegawai KPK yang tidak lulus TWK, sehingga tidak jarang Febri Diansyah sering menjadi Opinion Leaders dari pihak yang kontra terhadap isu ini, dikarenakan Febri Diansyah tergolong sebagai influencer yang memiliki banyak followers di akun Twitternya.

Kehadiran opinion leaders dalam polemik publik selalu bisa menjadi episentrum perdebatan. Susanto (2013) menyebutkan hadirnya seorang opinion leaders memiliki peran yang sangat kuat untuk menjadi sumber informan yang kredibel dan berperan dalam meyakinkan khalayak dalam khasanah komunikasi. Kampanye yang dilakukan oleh opinion leader terhadap isu-isu tertentu dalam menggiring opini publik di media sosial efektifnya dilakukan di platform Twitter. Algoritma yang dihadirkan oleh Twitter menyediakan keleluasan bagi penggunanya dalam bentuk penggunaan hashtag atau tagar yang jika dilakukan secara masif bisa menjadi trending topic. Sehingga tweet yang dihadirkan dalam polemik publik dapat diukur viralitasnya melalui analisis konten-konten tersebut (Putra dan Irwansyah 2020).

Hal yang menarik dalam polemik isu pemecatan pegawai KPK ini adalah tidak adanya muncul akun politisi atau pejabat yang mengomentari hal ini atau menjadi opinion leader, meskipun nama Jokowi banyak disebut dalam polemik. Begitupula dengan akun-akun politisi dan partai politik yang secara posisi sebagai oposisi tidak ada yang berkomentar terkait isu ini secara lantang.

Berdasarkan hasil dan pembahasan di atas, penelitian ini menggambarkan analisis konten polemik warganet di Twitter pada isu pemecatan pegawai KPK yang dilihat dari distribusi sentimen. Adanya distribusi sentimen yang terbangun antara sentimen positif dan negatif menunjukkan adanya komputasi mengenai emosi, pendapat, sikap, penilaian, padangan dari kumpulan teks sebagaimana hasil penelitian dari Fathan Hidayatullah (2014) dalam tweet yang diproduksi oleh warganet. Hal ini menjawab gambaran bagaimana Twitter memediasi isu pemecatan pegawai tidak lulus Tes Wawasan Kebangsaan (TWK) yang menjadi perdebatan di tengah warganet. Proses perdebatan terbangun melalui proses $e$ participation yang diadopsi dari Kneuer (2016) yakni information, monitoring, dialog, dan decision making. Pada isu pemecatan pegawai KPK RI yang tidak lulus TWK, terjadi adanya demokratisasi dalam ruang publik. Blommaert (2020) menyebut demokratisasi di ruang publik 
digital ditandai dengan adanya polemik yang memediasi wacana politik melalui pesan dan narasi yang disebarkan melalui media sosial twitter.

\section{PENUTUP}

Penelitian ini melihat distribusi sentimen dengan mengkategorisasikan tweet ke dalam beberapa kategori. Kategori terbanyak adalah Impresi dan kemudian yang paling sedikit adalah kategori Kekhawatiran. Dari distribusi sentimen, didominasi oleh sentimen negatif sebanyak 48\%. Peneliti kemudian memperdaam makna-makna di setiap distribusi sentimen dengan analisis wordcloud dan temuan peneliti salah satunya meneukan perbedaan penggunaan kata kerja pasif yang bermakna sama di tiap sentimen yaitu, pada sentimen positif kata kerja yang banyak digunakan adalah "dipecat", kemudian pada sentimen netral banyak menggunakan kata "diberhentikan", dan pada sentimen negatif banyak menggunakan kata "disingkirkan". Perbedaan kata kerja yang digunakan mempertegas makna pro dan kontra dari setiap distribusi sentimen.

Dalam segi perdebatan yang terjadi, perdebatan masih didominasi oleh kategori Impresi yang banyak membangun narasi labelling antar pihak. Dari segi aktor, opinion leader masih bersumber banyak dari akun-akun media massa, influencer, dan aktivis. Belum ada politisi atau pejabat yang ikut berpendapat dalam isu ini sebagai opinion leader.

Perdebatan yang terjadi di media sosial twitter tersebut menggambarkan bagaimana demokrasi digital terbangun, yaitu terlihat dari adanya demokratisasi warganet dalam mengutarakan keberpihakan, pendapat dan pandangannya terhadap isu pemecatan pegawai KPK yang tidak lolos TWK. Demokratisasi yang terbangun dalam polemik ini dapat terlihat juga dari e-partisipation yang muncul dalam beragam bentuk seperti informasi, dialog, monitoring, dan pengambilan keputusan warganet dalam menyikapi isu ini. Bentuk informasi dapat terlihat dari media sosial Twitter yang berperan memediasi wacana politik kepada masyarakat. Bentuk dialog terlihat dari kategori "Menyebut Pemerintah" yang menandakan adanya maksud dari warganet untuk membangun dialog atas isu yang dibangun terhadap pemerintah. Bentuk monitoring banyak diampu oleh media massa yang setiap waktu memonitoring perkembangan isu yang terjadi. Sedangkan bentuk pengambilan keputusan dapat dilihat dari penggunaan hashtag untuk mempertegas keberpihakan oleh warganet.

Kontribusi dan refleksi temuan dari penelitian ini adalah memetakan isu terkait dengan pemecatan pegawai KPK RI yang tidak lulus TWK agar mengetahui bagaimana perdebatan di ruang publik Twitter. Perdebatan ini dapat menjadi gambaran dari bagaimana demokratisasi di ruang publik siber terjadi melalui pembangunan narasi perdebatan antar sentimen. Aktivisme digital sebagai tanda dari demokrasi digital juga berjalan dengan munculnya hashtag-hashtag yang mewakili keberpihakan antar pihak. Meskipun, penelitian ini masih memiliki keterbatasan diantaranya dalam mengetahui siapa subjek sebenarnya dari akun-akun yang tidak menggunakan identitas asli, akan tetapi terlibat menjadi opinion leaders.

Rekomendasi penelitian lanjutan dari peneliti terhadap penelitian ini adalah terkait dengan analisis jaringan perdebatan yang dapat dilihat salah satunya melalui pendekatan Sosial Media Network Analysis (SMNA), sehingga dapat mengetahui jaringan-jaringan aktor (akun) dan jaringan kata yang saling berkaitan satu sama lain. Hal ini akan memperdalam peta polemik publik di dalam ruang media sosial Twitter. 


\section{REFERENSI}

Alwajih, Ahmad. 2014. "Dilema E-Democracy Di Indonesia: Menganalisis Relasi Internet, Negara, Dan Masyarakat." Jurnal Komunikasi 8(2):139-52. doi: 10.20885/komunikasi.vol8.iss2.art3.

Asenbaum, H. 2018. "Anonymity and Democracy: Absence as Presence in the Public Sphere." American Political Science Review $112 \quad$ (3):459-72. doi: doi:10.1017/S0003055418000163.

Barber, B. 2003. Which Democracy and Which Technology? Democracy and New Media. (Eds. ) Henry Jenkins and David Thorburn. Cambridge: Mass: The MIT Press.

Bergström, L. 2006. "Political Participation: A Qualitative Study of Citizens in Hong Kong." Dissertation, Karlstad University, Sweden 257. Retrieved October 7, 2021 (http://urn.kb.se/resolve?urn=urn:nbn:se:kau:di va-257).

Blommaert, Jan. 2020. "Political Discourse in Post-Digital Societies." Trabalhos Em Linguística Aplicada 59(1):390-403. doi: 10.1590/01031813684701620200408.

CNN Indonesia. 2021. "KPK Pecat 57 Pegawai Gagal ASN per 30 September 2021." CNN $\begin{array}{llll}\text { Indonesia. } & \text { Retrieved } & \text { January } & 13,\end{array}$ (https://www.cnnindonesia.com/nasional/20210915152958-12-694768/kpk-pecat-57pegawai-gagal-asn-per-30-september-2021).

Fathan Hidayatullah, Ahmad, and Azhari Sn. 2014. "ANALISIS SENTIMEN DAN KLASIFIKASI KATEGORI TERHADAP TOKOH PUBLIK PADA TWITTER." Seminar Nasional Informatika 2014(semnasIF):115-22.

Franzosi, Roberto. 2008. "Content Analysis: Objective, Systematic, and Quantitative Description of Content." Content Analysis xxi-xlix.

Gramsci, Antonio, Quintin Hoare, et al. 1971. Selections from the Prison Notebooks of Antonio Gramsci. Lawrence \& Wishart.

Haezer, Eben. 2018. "Menyoal Internet Sebagai Ruang Publik Dalam Perspektif Habermas." Dakwatuna: Jurnal Dakwah Dan Komunikasi Islam 4(2):181. doi: 10.36835/dakwatuna.v4i2.301.

Hamid, Abdulloh, Darwis Darwis, and Santi Andriyani. 2018. "Fenomena Politik Cebong Dan Kampret Di Indonesia: Sebuah Analisis Dari Perspektif Pemikiran Politik Dalam Islam.” Politea 1(1):29. doi: 10.21043/politea.v1i1.4320.

Hananto, Prio. 2014. "Opinion Leader versus New Opinion Leader Dalam Komunikasi Pemasaran (Studi Kasus Selebtwit Di Twitter Untuk Komunikasi Pemasaran)." Interaksi: Jurnal Ilmu Komunikasi 3(2):140-53. doi: 10.14710/interaksi.3.2.140-153.

Joosten, Simon A., Kais Hamza, Scott Sands, Anthony Turton, Philip Berger, and Garun Hamilton. 2012. "Phenotypes of Patients with Mild to Moderate Obstructive Sleep Apnoea as Confirmed by Cluster Analysis." Respirology 17(1):99-107. doi: 10.1111/j.1440-1843.2011.02037.x.

Jurgen Habermas. 2008. Ruang Publik Jurgen Habermas Sebuah Kajian Tentang Kategori Masyarakat Borjuis. Yogyakarta: Kreasi Wacana Yogyakarta.

Kent, M. L. 2013. "Using Social Media Dialogically: Public Relations Role in Reviving Democracy." Public Relations Review 39(4):337-45.

Kneuer, Marianne. 2016. "E-Democracy. A New Challenge for Measuring Democracy." International Political Science Review 37:666-78.

Kurnia, N. \& Savirani, A. (eds. .. 2021. Big Data Untuk Ilmu Sosial: Antara Metode Riset Dan Realitas Sosial. Yogyakarta: Gadjah Mada University Press.

Mauliansyah, Fiandy. 2016. "THE SOCIAL AND POLITICAL ASPECTS OF NEW MEDIA (Menelusuri Jejak Kesadaran Dan Tindakan Kolektif Massa)." SOURCE : Jurnal Ilmu Komunikasi 2(2). doi: 10.35308/source.v2i2.404. 
Moleong, Lexy J. 2012. Metode Penelitian Kualitatif. Bandung: PT Remaja Rosdakarya.

Nomleni, Petrix, Mochamad Hariadi, and I. Ketut Eddy Purnama. 2014. "Sentiment Analysis Berbasis Big Data." Seminar Nasional Rekayasa Teknologi Industri Dan Informasi 9:142-49.

Poentarie, Emmy. 2015. "The Comparison of Truth, Relevance, Balance and Netrality in News Reporting." Jurnal Studi Komunikasi Dan Media 19(1):1-13.

Pontes, A., Hen, M., and M. D. Griffiths. 2018. "Towards a Conceptualization of Young People's Political Engagement: A Qualitative Focus Group Study. Societies.” Societies 8. doi: doi: 10.3390/soc8010017.

Putra, Ariandi, and Irwansyah Irwansyah. 2020. "Orkestrasi Buzzer Melalui Media Sosial Microblogging Dalam Kampanye Penanganan Virus Covid-19.” Jurnal Riset Komunikasi 3(2):269-89. doi: 10.38194/jurkom.v3i2.151.

Ragini, J. R., P. M. R. Anand, and V. Bhaskar. 2017. "Big Data Analytics for Disaster Respondsean Recovery through Sentiment Analysis." International Journal of Information Management 42:13-24. doi: https://doi.org/10.1016/j. ijinfomgt.2018.05.004.

Rozi, Pramono, and E. A. Dahlan. 2012. "Implementasi Opinion Mining (Analisis Sentimen) Untuk Ekstraksi Data Opini Publik Pada Perguruan Tinggi." Jurnal EECCIS 6(1):37-43.

Shull, P. B., Y. Jiang, S., Zhu, and X. Zhu. 2019. "Hand Gesture Recognition and Finger Angle Estimation via Wrist-Worn Modified Barometric Pressure Sensing." IEEE Transactions on Neural Systems and Rehabilitation Engineering 27(4):724-732. doi: https://doi.org/10.1109/ TNSRE.2019.2905658.

Sugiyono. 2011. Metode Penelitian Kuantitatif, Kualitatif Dan R\&D. Bandung: Alfabeta.

Susanto, E. H. 2013. Komunikasi Politik. Mitra Wacana Media.

Tsagarousianou, R. 1999. "Electronic Democracy: Rhetoric and Reality." Communications: The European Journal of Communication Research 24 (2):189-208.

Yamada, K. 2020. "Public Response to News Reports on the Mount Kusatsu-Shirane Volcanic Eruption: A Content Analysis of Online Reader Comments." International Journal of Disaster Risk Reduction 43(101388). doi: https://doi.org/10.1016/j.ijdrr.2019.10138.

Yuli Isnadi. 2021. "Polemik KPK Dan Titik Bara Kekecewaan." Detik News. Retrieved January 13, 2022 (https://news.detik.com/kolom/d-5744661/polemik-kpk-dan-titik-barakekecewaan). 